\title{
Amine bridges grafted mesoporous silica, as a prolonged/controlled drug release system for the enhanced therapeutic effect of short life drugs
}

Fozia Rehman ${ }^{1,2}$, Khalid Ahmed ${ }^{1}$, Claudio Airoldi ${ }^{1}$, Simon Gaisford ${ }^{3}$, Asma Buanz ${ }^{3}$, Abdur Rahim $^{2}$, Nawshad Muhammad ${ }^{2}$ and Pedro L. O. Volpe ${ }^{1}$

1. Institute of Chemistry, University of Campinas, UNICAMP, P.O. Box 6154, 13084-971 Campinas, SP, Brazil

2. Interdisciplinary Research Centre in Biomedical Materials (IRCBM), COMSATS Institute of Information Technology, Lahore, Pakistan

3. UCL School of Pharmacy, University College London, 29-39 Brunswick Square, London, WC1N 1AX, UK

Abstract;

Hybrid mesoporous silica SBA-15, with surface incorporated cross-linked long hydrophobic organic bridges was synthesized using stepwise synthesis. The synthesized materials were characterized by elemental analysis, infrared spectroscopy, nuclear magnetic resonance spectroscopy, nitrogen adsorption, X-rays diffraction, thermogravimetry and scanning and transmission electron microscopy. The functionalized material showed highly ordered mesoporous network with a surface area of $629.0 \mathrm{~m}^{2} \mathrm{~g}^{-1}$. The incorporation of long hydrophobic amine chains on silica surface resulted in high drug loading capacity (21\% Mass/Mass) and prolonged release of ibuprofen up till $75.5 \mathrm{~h}$. The preliminary investigations suggests that the synthesized materials could be proposed as controlled release devices to prolong the therapeutic effect of short life drugs such as ibuprofen to increase its efficacy and to reduce frequent dosage.

Keywords: Mesoporous silica, surface modification, ibuprofen and controlled drug release.

Corresponding author Tel.: +55 19-35213055, Fax: + 55 19-35213023

*Email address: foziaics@yahoo.com 


\section{Introduction}

Among porous materials, mesoporous silica $\left(\mathrm{SiO}_{2}\right)$ has attracted much attention in the recent years due to their highly ordered porous network, extremely high surface area $1500 \mathrm{~m}^{2} \mathrm{~g}^{-1}$, large pore volume and tunable/uniform pore and particle size. The high surface silanol (Si-OH) density of these materials permits the tailoring of the surface properties such as hydrophilicity, and binding of molecular entities. The surface functionalization of $\mathrm{SiO}_{2}$ with organic molecules is emerged as one of the most important research areas in the field of advanced functional materials [1]. The versatile nature of mesoporous $\mathrm{SiO}_{2}$ attracted great deal of attention in various applied fields such as adsorption [2], catalysis [3], drug and gene delivery [4,5], imprinting for molecular recognition [6] etc.

Controlled release systems have been devised to enable superior control of drug exposure over time, to assist drug in crossing physiological barriers, to shield drug from premature elimination, and to shepherd drug to the desired site of action while minimizing drug exposure elsewhere in the body. These carriers systems may also increase patient compliance by reducing frequency of administration, and may add commercial value to marketed drugs by extending patent protection. Mesoporous silica materials have been intensively investigated as a carrier for controlled and targeted drug release, gene and enzyme immobilization [7-9], enabling them to retain their activity after reaching to the specific targeted site. These materials have the significant advantage of being free from various biochemical attacks and bioerosions. In addition to their high drug loading capacity and controlled/sustained release pattern, their biocompatible and nontoxic nature has attracted a great deal of research attention for various controlled release systems [10].

The physiochemical properties, such as surface charge, surface topography of biomaterials has great influence on its biocompatibility [11,12]. In mesoporous silica the surface exposed silanol group (about $6 \%$ of the total of the particles) can interact with cellular membrane lipids and proteins [13]. Mesoporous silica would rapidly associate with serum opsonin, and then could be removed from circulation by macrophages in reticuloendothelial system (RES) after entering into the blood stream [14]. Some studies also suggest that surface modification plays pivotal role in altering the surface reactivity, improving the biocompatibility and increasing in vivo circulation time [15]. The in vitro cellular uptake and cytotoxicity, in vivo biodistribution and excretion of mesoporous $\mathrm{SiO}_{2}$ can be regulated by surface modification with functional 
groups such as amino $\left(-\mathrm{NH}_{2}\right)$, carboxyl (-COOH), phenyl (-Ph), and methyl phosphonate $\left(-\mathrm{PO}_{3}{ }^{-}\right)$ groups [14]. Modified mesoporous $\mathrm{SiO}_{2}$ with amino groups, could manipulate the particle endocytosis [15].

Among mesoporous silicas, SBA-15 with large surface area up to $1500 \mathrm{~m}^{2} \mathrm{~g}^{-1}$, pore volume $\left(\sim 1.5 \mathrm{~cm}^{3} \mathrm{~g}^{-1}\right)$ and facile surface modification promise great opportunities to obtain functional biomaterials with improved and tailored properties [16]. The large pore diameter of this silica is also important and beneficial for accommodation of large molecular weight enzymes and proteins. SBA-15 has two-dimension hexagonal pore channels that allow loaded drug molecules to directly diffuse outwards. Moreover, both the opposite potential and the similar hydrophilicity between silica and drug molecules also favor the sustained/prolonged release of drugs. Compared to the negatively charged silica, the positive-charge modified silica materials exhibited remarkably sustained release profiles [17].

Drug loading, generally is a quite complex issue and much efforts were focused on improving drug loading capacity and prolonged therapeutic effect. Surface modification is one of such ways to achieve high drug loading capacity and prolonged/controlled release over an extended time period. Similarly, the diffusion rate of the drug molecules depends on the carrier type [18]. Ibuprofen is an extensively prescribed analgesic and anti-inflammatory drug with a relatively narrow therapeutic range that rapidly eliminate from the body. The efficacy of this drug would be enhanced by protecting it from physiological degradation before absorption. The structure of ibuprofen contains one carboxylic acid group, which can form the stronger bonding with many functional groups such as amines via acid base reaction. Ibuprofen has been also reported as a model drug to study the loading and release profiles from porous systems such as mesoporous silica based carriers. The good pharmacological activity and the suitable molecule size of about $1.0 \times 0.6 \mathrm{~nm}$ [19], ensures its easy diffusion into or out of the mesoporous channels of mesoporous silica. Thus the efficacy of this drug would be enhanced by loading it to mesoporous channels of silica to protect it from physiological degradation before absorption.

Hence the aim of this work is to synthesize mesoporous silica SBA-15 with hydrophobic organic functionality for controlled release of ibuprofen. For this purpose modified silica, SBA15TPA with long hydrophobic chains of tetraethylenepentamine (TPA) was synthesized and tested for the in vitro controlled release of ibuprofen. The sustained/controlled release capacities 
of the ibuprofen-loaded materials were investigated. The structure and synthesis route of functionalized silica is illustrated in scheme 1 .

\section{Experimental}

\subsection{Reagents}

All reagents and solvents were of analytical grade and used as received. Tetraethylorthosilicate (TEOS), 3-chlropropyltriethoxysilane, tetraethylenepentamine (TPA), coblock polymer Pluronic $\mathrm{P}_{123}$, sodium hydroxide $(\mathrm{NaOH})$, sodium chloride $(\mathrm{NaCl})$, sodium bicarbonate $\left(\mathrm{NaHCO}_{3}\right)$, sodium carbonate $\left(\mathrm{Na}_{2} \mathrm{CO}_{3}\right)$, potassium chloride $(\mathrm{KCl})$, potassium phosphate dibasic trihydrate $\left(\mathrm{K}_{2} \mathrm{HPO}_{4} \cdot 3 \mathrm{H}_{2} \mathrm{O}\right)$, magnesium chloride hexahydrate $\left(\mathrm{MgCl}_{2} \cdot 6 \mathrm{H}_{2} \mathrm{O}\right)$, calcium chloride $\left(\mathrm{CaCl}_{2}\right)$, sodium sulphate $\left(\mathrm{Na}_{2} \mathrm{SO}_{4}\right)$, and tris(hydroxymethyl)aminomethane $\left(\mathrm{NH}_{2} \mathrm{C}\left(\mathrm{CH}_{2} \mathrm{OH}\right)_{3}\right.$, were Sigma Aldrich products. Ethanol, Xylene and $\mathrm{HCl}$ were Synth products. Ibuprofen (IBU) was donated by Galena Pharma Campinas-Brazil and deionized water was used throughout the experiment.

\subsection{Synthesis of mesoporous silica}

Mesoporous silica SBA-15 was synthesized according to a reported method [20]. Briefly, for the synthesis of $1.0 \mathrm{~g}$ of SBA-15, $2.0 \mathrm{~g}$ of surfactant polymer Pluronic $\mathrm{P}_{123}$ was dissolved in $12.0 \mathrm{~cm}^{3}$ of deionised water at $313 \mathrm{~K}$, followed by the addition of $60.0 \mathrm{~cm}^{3}$ of hydrochloric acid $\left(2.0 \mathrm{~mol} \mathrm{dm}^{-3}\right)$ and the solution was stirred for $4 \mathrm{~h}$. After this step, $4.0 \mathrm{~g}$ of TEOS was added drop wise on stirring and the resulted white suspension was kept in an autoclave for crystallization, under static conditions in a polypropylene bottle for $24 \mathrm{~h}$ at $373 \mathrm{~K}$. The white suspended SBA-15 silica was then filtered, washed several times with deionized water and dried at room temperature and calcined in air at $873 \mathrm{~K}$ for $6 \mathrm{~h}$ to remove the template.

To obtain amine grafted SBA-15TPA silica, $36.0 \mathrm{mmol}\left(5.4 \mathrm{~cm}^{3}\right)$ of 3chloropropyltriethoxysilane was reacted with $18.0 \mathrm{mmol}\left(3.4 \mathrm{~cm}^{3}\right)$ of tetraethylenepentamine in $50.0 \mathrm{~cm}^{3}$ of ethanol. This mixture was stirred for $72 \mathrm{~h}$ at $323 \mathrm{~K}$ under anhydrous nitrogen atmosphere. The resultant bridged silylating agent (Scheme 1) was then transferred to a threenecked round bottom flask, containing $1.0 \mathrm{~g}$ of the prepared SBA-15 (calcined), suspended in xylene. The reaction mixture was kept on stirring under dry nitrogen for another $72 \mathrm{~h}$ at $348 \mathrm{~K}$ 
and the resultant solid of modified silica (SBA-15TPA) was filtered, washed and dried under vacuum at room temperature.

Please insert scheme 1 here.

\subsection{Drug loading}

The drug loading was achieved by soaking the silica samples each $0.5 \mathrm{~g}$ into $50 \mathrm{~cm}_{3}$ of ibuprofen solution $\left(10.0 \mathrm{~g} \mathrm{dm}^{3}\right)$ prepared in hexane in tightly closed flasks. After 3 days each drug-loaded material was filtered and dried at $333 \mathrm{~K}$. To measure the drug loading, $3.0 \mathrm{~cm}^{3}$ of each filtrate was diluted to $50.0 \mathrm{~cm}^{3}$ and the absorbance of these samples was measured at $\mathrm{UV} / \mathrm{Vis}$ spectrometer at $265 \mathrm{~nm}$. Pure drug powder was used to prepare calibration standards of known drug concentration, which was set up with each assay. The drug loading content (\% Mass/Mass) [21] was calculated with Equation 1.

$w t \%=\frac{m_{1}-\frac{50}{v} C V}{m_{2}+\left(m_{1}-\frac{50}{v} C V\right)} 100$

where $m_{1}$ is the initial mass of the drug, $m_{2}$ is the initial mass of silica, $C$ is the concentration of each filtrate diluted in $50.0 \mathrm{~cm}^{3}$ volumetric flasks, $v$ is sampled volume from filtrate and $V$ is the volume of solvent used for drug loading.

\subsection{In vitro drug release}

In vitro drug release testing is an experimental methodology which is used to characterize and compare the release properties of modified formulations. To provide an accurate estimate of the ibuprofen release from the prepared silicas in-vitro release test/dissolution test was performed using physiological condition. For this purpose different $\mathrm{pH}$ solutions i.e. simulated gastric fluid (SGF/ $0.10 \mathrm{~mol} \mathrm{dm}^{-3} \mathrm{HCl}, \mathrm{pH} 1.2$, without pepsin) simulated body fluid (SBF, pH 7.2) and simulated intestinal fluid (SIF/Phosphate Buffer, $\mathrm{pH}$ 6.8, USP 25) were used as drug release/dissolution media to simulate normal blood/tissue environment [22]. The simulated gastric fluid $\left(0.10 \mathrm{~mol} \mathrm{dm}^{-3}\right)$ of $\mathrm{pH} 1.2$ was prepared by mixing appropriate volume of $\mathrm{HCl}$ in 1.0 $\mathrm{dm}^{3}$ of deionized water. The simulated body fluid (SBF pH 7.2, USP ) was prepared by dissolving $\mathrm{NaCl}(7.996 \mathrm{~g}), \mathrm{NaHCO}_{3}(0.350 \mathrm{~g}), \mathrm{KCl}(0.224 \mathrm{~g}), \mathrm{K}_{2} \mathrm{HPO}_{4} .3 \mathrm{H}_{2} \mathrm{O}(0.228 \mathrm{~g})$, 
$\mathrm{MgCl}_{2} .6 \mathrm{H}_{2} \mathrm{O}(0.305 \mathrm{~g}), 1.0 \mathrm{~mol} \mathrm{dm}{ }^{-3} \mathrm{HCl}\left(40 \mathrm{~cm}^{3}\right), \mathrm{CaCl}_{2}(0.278 \mathrm{~g}), \mathrm{Na}_{2} \mathrm{SO}_{4}(0.071 \mathrm{~g})$, tris(hydroxymethyl)-aminomethane $\left(\mathrm{NH}_{2} \mathrm{C}\left(\mathrm{CH}_{2} \mathrm{OH}\right)_{3}(6.057 \mathrm{~g})\right.$ in $1.0 \mathrm{dm}^{3}$ of deionized water. While $0.05 \mathrm{M}$ buffer solution of potassium dihydrogen phosphate was used as SIF with pancreatin (USP 26).

To check drug release pattern, each $50.0 \mathrm{mg}$ of the loaded samples (pressed disks at pressure 5.0 MPa) were putted in $500 \mathrm{~cm}^{3}$ of each simulated fluids placed in three different plastic vials. The tightly closed vials were then placed in an orbital shaking incubator (MA-420 MARCONI-Brazil) at a stirring rate of $75 \mathrm{rpm}$ in a light-sealed condition at $37 \pm 0.5^{\circ} \mathrm{C}(\mathrm{Ph}$. Eur. 4/ USP 26). At a predetermined time interval of $0.5 ; 1.0 ; 3.5 ; 7.0 ; 8.5 ; 21.0 ; 24.0$ and $72.5 \mathrm{~h}, 3.0$ $\mathrm{cm}^{3}$ of the release media were taken out for measuring the concentrations of the drug released. A corrected method [21] was used to estimate the real amount of the drug released from mesoporous silica (Equation 2). The absorbance of the samples was measured using UV/Vis spectrophotometer.

$C_{t-\mathrm{corr}}=C_{t}+\frac{v}{V} \sum_{0}^{t-1} C_{t}$

where $\mathrm{C}_{\mathrm{t}-\mathrm{corr}}$ is the actual concentration of drug released at time $\mathrm{t}, C_{t}$ is the measured concentration of the release fluid sampled at time $\mathrm{t}, v$ is the sampled volume taken at a predetermined time interval, and $V$ is the total volume of release fluid.

\subsection{Characterization}

Fourier transform infrared spectra were obtained by accumulating scans on a Bomem MBseries spectrophotometer with $\mathrm{KBr}$ pellets, in the 4000 to $400 \mathrm{~cm}^{-1}$ range, with an accumulation of 32 scans and $4 \mathrm{~cm}^{-1}$ of resolution. Elemental analysis was performed on a Perkin-Elmer PE2400 instrument. Nuclear magnetic resonance spectra (in solid state) were recorded on a Bruker Advance 3-300 MHz spectrometer at room temperature. For each run approximately one gram of solid sample was compacted in $4 \mathrm{~mm}$ zirconium oxide rotors and the measurements were obtained at frequencies of 59.63 and $75.47 \mathrm{MHz}$ with a spinning magic angle of $10 \mathrm{MHz}$, for

silicon and carbon atoms, respectively. ${ }^{29} \mathrm{Si}$ and ${ }^{13} \mathrm{C} \mathrm{CP} / \mathrm{MAS}$ spectra were obtained with pulse repetitions of $3 \mathrm{~s}$ for both nuclei and contact times of $4 \mathrm{~ms}$. Nitrogen sorption was performed 
with a Micromeritics ASAP 2000 or Quantachrome Autosorb using nitrogen at $77 \mathrm{~K}$ and the samples were degassed for $8 \mathrm{~h}$ at $363 \mathrm{~K}$ before taking the measurements. Small angle X-ray analyses were performed using synchrotron light on the D11A-SAXS line with a wavelength of $0.1488 \mathrm{~nm}$. Thermogravimetric analyses were performed with thermal balance model $1090 \mathrm{~B}$, under argon, with a flow rate $30 \mathrm{~cm}^{3} \mathrm{~s}^{-1}$, from room temperature to $1200 \mathrm{~K}$, with heating rate $0.167 \mathrm{~K} \mathrm{~s}^{-1}$. SEM images were taken with (SEM) with JEOL JS 6360-LV and TEM was performed with JEOL FE6 2700 equipment. The zeta potential was measured with MalvernNano-ZS Zetasizer. For pH measurements SevenEesy Metter Toledo pH meter was used. The drug sorption and release experiments were monitored by using a Shimadzu Multispec-1501 $\mathrm{UV} / \mathrm{Vis}$ spectrophotometer. To monitor the drug concentration at specific intervals, the mixture was centrifuged at $4000 \mathrm{rpm}$ using a Rotina 38 Hittich Zentrifugen centrifuge. The drug release experiments were performed in an orbital shaking incubator model MA-420-MARCONI-Brazil.

\section{Result and discussion}

\subsection{Elemental analysis}

The carbon and nitrogen contents of the modified silica were found $9.14 \%$ and $3.58 \%$, respectively. The $\mathrm{mmol} \mathrm{g}^{-1}\left(\mathrm{~L}_{\mathrm{o}}\right)$ quantities of carbon and nitrogen were calculated with Equation 3 and estimated to be $7.62 \mathrm{mmol} \mathrm{g}^{-1}$ and $2.75 \mathrm{mmol} \mathrm{g}^{-1}$ respectively.

$L_{O}=\frac{\% \text { Element } \times 10}{m_{a}}$

where is $m_{a}$ is the atomic mass of element. A very close agreement was observed between the theoretical $(\mathrm{C} / \mathrm{N} 2.8)$ and experimental carbon and nitrogen molar ratios $(\mathrm{C} / \mathrm{N} 2.8)$. The degree of

functionality $(\delta)$ was calculated by dividing the $\mathrm{mmol} \mathrm{g}^{-1}$ of nitrogen with the number of nitrogen atoms present in the single bridged chain. The modified silica SBA-15TPA, showed a good degree of functionality $(\delta)$ of about $0.55 \mathrm{mmol} \mathrm{g}^{-1}$, which suggests the modification of SBA-15 silica.

\subsection{Infrared Spectroscopy}


Typical bands associated with the inorganic backbone of mesoporous silica, as well as with the anchored TPA bridges are shown in Figure 1. Band appeared at $3500 \mathrm{~cm}^{-1}$ can be attributed to $\mathrm{OH}$ stretching frequency, while the bands in the 1620 to $1630 \mathrm{~cm}^{-1}$ interval can be assigned to $\mathrm{OH}$ bending vibration of water molecules sorbed onto the solid surface through hydrogen bonds, reinforcing the free silanol groups [23]. The bands in the 1000 to $1100 \mathrm{~cm}^{-1}$ interval can be assigned to Si-O-Si stretching vibrations and the band appeared at $961 \mathrm{~cm}^{-1}$ represents the free silanol groups ( $\mathrm{Si}-\mathrm{O}-\mathrm{H})$, which is less intense in the case of silica SBA-15TPA. This expected decrease in band intensity is related to the replacement of silanol groups with organic TPA bridges on silica surface to form the inorganic Si-O-Si bond. The presence of a small band at $2800-2931 \mathrm{~cm}^{-1}$ in the spectrum of SBA-15TPA was assigned to $\mathrm{v}(\mathrm{C}-\mathrm{H})$ stretching, while a new band at $1469 \mathrm{~cm}^{-1}$ (stretching band of C-N group) indicates that the organic group was covalently attached to silica surface [24] (Figure 1b). Peaks appeared in the range $1000-1100 \mathrm{~cm}^{-1}$ was assigned to $\mathrm{Si}-\mathrm{O}-\mathrm{Si}$ stretching bands.

Please insert Figure 1 here.

\subsection{NMR spectroscopy}

Resonance of the ${ }^{29} \mathrm{Si}$ nuclei allows the determination of its configuration based on different chemical shifts. The resonance at $-92,-100$ and $-110 \mathrm{ppm}$ in the ${ }^{29} \mathrm{Si}$ CP/MAS NMR spectrum of SBA-15 (Figure 2a) reflect the surface silanol groups, $\mathrm{Q}^{2}\left[(\mathrm{OSi})_{2}(\mathrm{OH})_{2}\right], \mathrm{Q}^{3}$ $\left[(\mathrm{OSi})_{3}(\mathrm{OH})\right]$ and $\left.\mathrm{Q}^{4}\left[\mathrm{Si}(\mathrm{OSi})_{4}\right)\right][25]$. While the signals at $-64 \mathrm{ppm}$ and $-56 \mathrm{ppm}$ in the spectrum of SBA-15TPA can be assigned to $\mathrm{T}^{2}\left(\mathrm{R}-\mathrm{Si}-(\mathrm{SiO})_{2}-\mathrm{ROH}\right)$ and $\mathrm{T}^{3}\left(\mathrm{R}-\mathrm{Si}-(\mathrm{SiO})_{3}\right)$ species (Figure $2 a)$, where $R$ is the organic molecule anchored to silylating agent. The appearance of these signals confirms the modification process. The above results suggest that the silylating agent with TPA bridges is connected to the inorganic network of silica SBA-15 in both bi and tridentate way, i.e. all of alkoxy groups suffered a condensation reaction. The intensity of these signals is related to surface coverage with silylating agents bearing organic groups.

The ${ }^{13} \mathrm{C}$ CP/MAS spectrum of the modified silica with bridged TPA chains is shown in Figure $2 \mathrm{~b}$. The chemical shifts at 9.3; 22; and $48 \mathrm{ppm}$ can be attributed C-Si, C-C, and C-N and assigned to $\mathrm{C} 1-\mathrm{C} 14$ of the inserted proposed structure in Figure 2b, which suggest the successful modification of silica surface.

Please insert Figure 2 here. 


\subsection{Small angle $X$-ray diffraction}

Small angle diffraction (SAXS) patterns of the prepared materials are shown in Figure 3. The obtained diffraction patterns indicated that the grafted organic groups did not affect the structural stability of the original mesoporous silica. A sharp reflection at $2 \theta$ near to 0.6 , indexed as (100) and two minor, but distinct reflections at $2 \theta$ in the interval 1.0 to 2.0 , were indexed as (110) and (200), respectively. These peaks were indexed according to two-dimensional hexagonal p6mm symmetry, with a well-defined SBA-15 mesostructure (Figure 3a), which is in agreement with the previously reported pattern for the same type silica material [23].

The diffraction patterns of modified silica before and after drug loading (Figure $2 \mathrm{~b}$ and 3c) indicate that the long-range hexagonal symmetry of SBA-15 is preserved after modifications with TPA chains. A slight decrease in intensity of these characteristic diffraction planes after modification or drug loading is due to contrast matching between the silicate framework and the anchored TPA bridges or loaded drug molecules [24]. The $d_{100}$ spacing at the (100) plane was calculated using Bragg's law as given in Equation 4:

$\lambda=2 \mathrm{~d}_{100} \sin \theta$

where, $\lambda$ is the wavelength and $\theta$ is the angle of incidence. The unit cell parameter $\left(\mathrm{a}^{0}\right)$ was calculated using Equation 5 and found to be $15.2 \mathrm{~nm}$ for both silicas.

$\mathrm{a}_{0}=2 \mathrm{~d}_{100} / \sqrt{ } 3$

Please insert Figure 3 here.

\subsection{Nitrogen Sorption/Desorption}

The nitrogen sorption/desorption isotherms of SBA-15 and modified silica SBA-15TPA are shown in Figure 4. The hysteresis loops with sharp adsorption and desorption branches, indicatives of a narrow mesopores size distribution and shows a typical characteristic type IV isotherm with H1 hysteresis loop [26]. The amount of sorbed volume increased significantly to relative pressure $\left(\mathrm{p} / \mathrm{p}^{0}\right)$, which is due to capillary condensation of nitrogen within the mesopores.

The grafting of long hydrophobic amine chains onto mesoporous surface resulted in a noticeable change in the adsorption characteristics of this silica. The BET surface area of SBA- 
15 decreased from $873.0 \mathrm{~m}^{2} \mathrm{~g}^{-1}$ to $629.0 \mathrm{~m}^{2} \mathrm{~g}^{-1}$ after modification. Similarly, when compared to original precursor silica SBA-15, the average pore volume decreased from $1.05 \mathrm{~cm}^{3}$ to $0.93 \mathrm{~cm}^{3}$ while, the BJH average pore diameter of modified silica $(7.1 \mathrm{~nm})$ was not changed significantly when compared to original precursor silica $(7.2 \mathrm{~nm})$. The pore wall thickness $P_{w}$ was calculated using Equation 5 and were estimated to be 8.0 and $7.9 \mathrm{~nm}$ for SBA-15 and modified silica, respectively.

$$
\mathrm{P}_{\mathrm{w}}=\mathrm{a}_{0}-\mathrm{D}_{\mathrm{p}}
$$

where, $\left(\mathrm{D}_{\mathrm{p}}\right)$ is the pore diameter obtained from nitrogen sorption/desorption and $a_{0}$ was calculated from the XRD data.

Please insert Figure 4 here.

\subsection{Scanning and Transmission electron microscopy}

The surface morphologies of the synthesized materials were investigated with both scanning electron microscopy (SEM) and transmission electron microscopy (TEM) as shown in Figure 5. The SEM images of SBA-15 (Figure 5A) show a channel-like porous structure with long fibrous macrostructures which is a characteristic morphology of SBA-15 type silica [17,24]. SEM for modified and IBU loaded silicas showed the same pattern morphological pattern (Figure 5B \& C). The size, shape of particles and agglomerates suggested highly ordered mesoporous fiber like structures and confirm that the original morphology of SBA-15 remained preserved after modification.

TEM image of SBA-15 (Figure 5D) showed bright and dark area correspond to pores and walls confirming well-ordered hexagonal arrays of mesopores (1D channel) and 2D p6mm hexagonal structure [27]. The distance between mesopores was estimated to be 7 to $10 \mathrm{~nm}$ for silica SBA-15 (Figure 5D), which is in agreement with SAXS data.

Please insert Figure 5 here.

\subsection{Thermogravimetry}

The thermogravimetric curves (TG) recorded for SBA-15 and SBA-15TPA are shown in Figure 6. TG curve of SBA-15 showed two distinct mass loss regions: i) in the temperature 
range from 314 to $335 \mathrm{~K}$ that correspond to $10 \%$ of total mass loss and ii) a slight decrease in mass of about $0.51 \%$ in the $335-1200 \mathrm{~K}$ range. The first event can be attributed to evaporation/decomposition of water and solvent molecules and the second event could be assigned to silanol condensation [27,28].

The DTG curve obtained for the chemically modified silica SBA-15TPA (Figure 6), has four distinct mass loss regions: i) about $4.0 \%$ in the temperature range 308 to $336 \mathrm{~K}$, that can attributed to the release of the trapped solvent or water molecules from porous network ii) a total mass loss of about $19.7 \%$ in the temperature range 336-793 $\mathrm{K}$ represents the decomposition of organic chains covalently bonded to silica surface. The mass loss above $793 \mathrm{~K}$ can be attributed to the condensation of the silanol groups to yield Si-O-Si groups.

\section{Please insert Figure 6 here.}

\subsection{Zeta potential}

The zeta potential of silica SBA-15 and modified silica SBA-15TPA suspended in aqueous medium was measured and compared. The $\zeta$ changed from -19 to $+45.7 \mathrm{mV}$ after modification. This high zeta potential value confirmed the modification process and also suggests the coverage of silica surface with basic -NH groups.

\subsection{Drug loading and in vitro release}

The nature of drug, physiological conditions, drug matrix interaction, surface charges and pore diameter in case of porous materials play a vital role in drug loading and release processes. At lower pH ibuprofen (pKa 4.91) dissociates to yields negatively charged carboxylate ions $\left(\mathrm{COO}^{-}\right)$and form strong bonding with free silanol $(-\mathrm{Si}-\mathrm{OH})$ or amine groups $\left(-\mathrm{N}^{+}\right)$of the anchored organic functional groups [28]. The amount of drug loaded by both unmodified (18\%) and modified (22\%) silicas indicated that the attached functional groups and mesoporous structure are responsible in the drug loading process.

In vitro drug release profiles (\% Mass/Mass) from silica systems in biological fluids (up to $8.5 \mathrm{~h}$ and complete release profile up to $75.5 \mathrm{~h}$ ) are shown in Figure $7 \mathrm{~A}$ and $7 \mathrm{~B}$. Initially, burst release (about $28 \%$ in $8.5 \mathrm{~h}$ ) was observed from unmodified silica SBA-15 in both SBF and SIF. After surface modification with amine linkers the drug release was slow and about 19 to 20 
$\%$ of the total drug was released during $8.5 \mathrm{~h}$ in SBF and SIF, respectively. While in simulated gastric fluid (SGF $0.10 \mathrm{~mol} \mathrm{dm}^{-3} \mathrm{HCl}$, pH 1.2) a slow release pattern (>10\% Mass/Mass) was observed from both unmodified and modified silicas, which could be possible due to i) adhesion of drug molecules into micro/mesopores of silica and ii) strong hydrogen bonding between surface silanols groups $(-\mathrm{Si}-\mathrm{OH})$ of SBA-15 or amine groups $\left(-\mathrm{N}^{+}\right)$of the modified silica with dissociated drug molecules of ibuprofen in strong acidic medium [29].

When the release medium was changed to simulated body fluid (SBF, pH 7.2, USP) at this $\mathrm{pH}$ condition, the low $\mathrm{H}+$ concentration favor the release of drug to medium, resulting in high release rate. In simulated intestinal fluid (SIF, Phosphate Buffer, $\mathrm{pH}$ 6.8) protons (H+) produced from drug dissociation can be partially consumed due to buffer action which can shift the equilibrium from surface to the release medium [28,29] and increase the drug solubility in comparison to other fluids. From the drug release profiles it is clear that the release equilibrium rates of SBA-15 are much faster than that of the modified silica with amine linkers (Figure 7). Hydrogen bonding between ibuprofen and parent silica material is relatively weaker, than that of

$-\mathrm{COO}^{-} \mathrm{NH}^{+}$bond of the modified silica and the release of IBU through the mesoporous channels is controlled by diffusion. The drug release process was gradually fallen after 24 and the release rate remained constant up to $75.5 \mathrm{~h}$ (Figure $7 \mathrm{~B}$ ).

Please inert Figure 7 here.

\subsection{Release mechanism}

The drug release mechanism from mesoporous silicas was investigated with zero order and first order kinetic models [30], Higuchi [31], Hixson Crowell [32], Korsmeyer-Peppas [3134] models as given in Equations 7-11.

Zero order model: $\quad \frac{M_{i}}{M_{t}}=k t$

First order model: $\quad \ln \left(1-\frac{M_{i}}{M_{t}}\right)=-k t$

Higuchi model: $\quad \frac{M_{i}}{M_{t}}=k \sqrt{t}$ 
Hixson-Crowell model: $\quad \sqrt[3]{1-\frac{M_{i}}{M_{t}}}=-k t$

Korsmeyer-Peppas model: $\quad \ln \frac{M_{i}}{M_{t}}=n \operatorname{Int}+\operatorname{Ink}$

where in these equations $M_{i} / M_{t}$ is the fractional active agents released at time $t, k$ is rate constant and $\mathrm{n}$ is an indication of such mechanism. The correlation coefficient $\mathrm{R}^{2}$ values obtained with Equations 7-11 are given in Table 1 . The low $\mathrm{R}^{2}$ values rejected the existence of linear fit of these models for both initial (up to $8.5 \mathrm{~h}$ ) and complete release data up to $75.5 \mathrm{~h}$. The release data was further processed with a non-linear fit of Korsmeyer-Peppas [31] using Equation 12:

Korsmeyer-Peppas model: $\quad \frac{M_{t}}{M_{\infty}}=k t^{n}$

where, $M_{t}$ and $M_{\infty}$ are the masses of drug released at time $t$ and at infinite time respectively, $k$ is kinetic constant and diffusional exponent $n$ is used to characterize the mechanism. For tablets, (depending on the diameter-thickness ratio) the Fickian diffusion is described by $0.43<n<0.50$ and $0.45<n<0.89$ corresponds to a non-Fickian or anomalous diffusion. The $n$ value of about 0.89 is an indicative of case II transport and for $n>0.89$ is typical zero-order release [29].

The correlation coefficient $\left(\mathrm{R}^{2}\right)$, diffusion exponent $n$ and rate constant $k$ values obtained from nonlinear fit of Korsmeyer-Peppas model (Equation 12) are given in Table 1. Exponent $n$ value less than 0.45 illustrated less Fickian diffusion mechanism of ibuprofen from both silicas. The small $k$ values at lower $\mathrm{pH}$ condition ( $\mathrm{pH}$ 1.2) indicate the slow release rate of ibuprofen from silica systems (due to protonation of IBU in acidic medium that ultimately increased the drug-silica interactions and resulted in slow diffusion rate). The large $k$ values obtained for high $\mathrm{pH}$ conditions illustrated the unrestricted diffusion of ibuprofen from silica systems to the dissolution medium (SBF, pH 7.2 and SIF pH 6.8). The modeling of the Korsmeyer-Peppas suggests that the drug release mechanism was more diffusion based due to highly accessible nano-reservoir of the silica materials.

Please insert Table 1 here. 


\section{Conclusion}

Mesoporous silica SBA-15 and its derivative SBA-15TPA was synthesized and characterized using sol gel method. Surface modification of the precursor silica with the synthesized long hydrophobic bridges improved the drug loading capacity and also affected the in vitro release profiles. Ibuprofen can make strong bonding with free silanol (-Si-OH) and amine groups $\left(-\mathrm{N}^{+}\right)$of the anchored organic functional groups this phenomenon was observed at $\mathrm{pH} 1.2$ conditions. The slow release kinetics at this $\mathrm{pH}$ favors to prevent the premature elimination of ibuprofen while passing through stomach that could enhance the drug availability at the desired site. The drug release mechanism from synthesized carriers was investigated with various kinetic models. The high correlation coefficient $\left(\mathrm{R}^{2}\right)$ and diffusion exponent $n$ value less than 0.45 obtained the nonlinear fit of Korsmeyer-Peppas illustrated less Fickian diffusion mechanism for ibuprofen from the proposed carrier systems. The synthesized material with porous network and surface functional groups could be proposed as a promising drug vehicle.

\section{Acknowledgment:}

The authors are indebted to TWAS/CNPq fellowships and support. To National Laboratory of Synchrotron Light (LNLS-Campinas, Brazil) for SAXS measurements and to National Laboratory of Nanotechnology (LNNano-Campinas) for TEM.

\section{References:}

1. R. Ciriminna, A. Fidalgo, V. Pandarus, F. Béland, L. Ilharco and M. Pagliaro, Chemical Reviews, 2013, 113, 6592-6620.

2. C. Knöfel, J. Descarpentries, A. Benzaouia, V. Zeleňák, S. Mornet, P. Llewellyn and V. Hornebecq, Microporous and Mesoporous Materials, 2007, 99, 79-85.

3. D. Do Van, T. Hosokawa, M. Saito, Y. Horiuchi and M. Matsuoka, Applied Catalysis A: General, 2015, 503, 203-208.

4. Y. Chen, Design, synthesis, multifunctionalization and biomedical applications of multifunctional mesoporous silica-based drug delivery nanosystems, Springer, 2015.

5. Y. Wang, Q. Zhao, N. Han, L. Bai, J. Li, J. Liu, E. Che, L. Hu, Q. Zhang, T. Jiang and S. Wang, Nanomedicine: Nanotechnology, Biology and Medicine, 2015, 11, 313-327. 
6. X. Hu, L. Xie, J. Guo, H. Li, X. Jiang, Y. Zhang and S. Shi, Food Chemistry, 2015, 179, 206-212.

7. A. Baeza, M. Colilla and M. Vallet-Regí, Expert Opinion on Drug Delivery, 2014, 12, 319-337.

8. J. Lai, B. Shah, Y. Zhang, L. Yang and K. Lee, ACS Nano, 2015, 9, 5234-5245.

9. B. Hung, Y. Kuthati, R. Kankala, S. Kankala, J. Deng, C. Liu and C. Lee, Nanomaterials, 2015, 5, 2169-2191.

10. M. Manzano and M. Vallet-Regí, Journal of Materials Chemistry, 2010, 20, 5593-5604.

11. N.J. Hallab, K. J. Bundy,K. O'connor,R. Clark, R.L. Moses, Journal of long-term effects of medical implants, 1994, 5, 209-231.

12. T. Suzuki, Y. Mizushima, Journal of fermentation and bioengineering, 1997, 84, 128 132.

13. Y. Zhao, X. Sun, G. Zhang, B.G. Trewyn, I.I. Slowing, V.S.Y. Lin,. ACS nano, 2011, 5, 1366-1375.

14. F. Tang, L. Li, D. Chen, Advanced Materials, 2012, 24, 1504-1534.

15. I.I. Slowing, B.G. Trewyn, V.S.Y. Lin, Journal of the American Chemical Society, 2006, $128,14792-14793$.

16. Y. Zhu, J. Shi, Y. Li, H. Chen, W. Shen and X. Dong, Microporous and Mesoporous Materials, 2005, 85, 75-81.

17. Q. He and J. Shi, Journal of Materials Chemistry, 2011, 21, 5845-5855.

18. J. Li, X. Du, N. Zheng, L. Xu, J. Xu and S. Li, Colloids and Surfaces B: Biointerfaces, 2016, 141, 374-381.

19. M. Vallet-Regi, A. Rámila, R. del Real and J. Pérez-Pariente, Chemistry of Materials, 2001, 13, 308-311.

20. D. Zhao, J. Sun, Q. Li and G. Stucky, Chemistry of Materials, 2000, 12, 275-279.

21. W. Xu, Q. Gao, Y. Xu, D. Wu, Y. Sun, W. Shen and F. Deng, Powder Technology, 2009, 191, 13-20.

22. A. Oyane, H. Kim, T. Furuya, T. Kokubo, T. Miyazaki and T. Nakamura, Journal of Biomedical Materials Research, 2003, 65A, 188-195. 
23. A. Prado, J. Sales, R. Carvalho, J. Rubim and C. Airoldi, Journal of Non-Crystalline Solids, 2004, 333, 61-67.

24. A. Heidari, H. Younesi and Z. Mehraban, Chemical Engineering Journal, 2009, 153, 7079.

25. D. Aiello, N. Folliet, G. Laurent, F. Testa, C. Gervais, F. Babonneau and T. Azaïs, Microporous and Mesoporous Materials, 2013, 166, 109-116.

26. M. Impéror-Clerc, P. Davidson and A. Davidson, Journal of American Chemical Society, 2000, 122, 11925-11933.

27. F. Rehman, A. Rahim, C. Airoldi and P. Volpe, Materials Science and Engineering: C, 2016, 59, 970-979.

28. F. Rehman, P. Volpe and C. Airoldi, Journal of Environmental Management, 2014, 133, 135-143.

29. C. Charnay, S. Bégu, C. Tourné-Péteilh, L. Nicole, D. Lerner, J. Devoisselle, European Journal of Pharmaceutics and Biopharmaceutics, 2004, 57, 533-540.

30. C. England, M. Miller, A. Kuttan, J. Trent and H. Frieboes, European Journal of Pharmaceutics and Biopharmaceutics, 2015, 92, 120-129.

31. J. Siepmann, Advanced Drug Delivery Reviews, 2001, 48, 139-157.

32. V. Puri and A. Bansal, Drug Development and Industrial Pharmacy, 2004, 30, 619-626

33. D. Samaha, R. Shehayeb and S. Kyriacos, Dissolution Technology, 2009, 16, 41-46.

34. U. Sharma, A. Verma, S. Prajapati, H. Pandey, A. Pandey, Applied Nanoscience, 2014, 5, 143-155. 
List of schemes:

Scheme 1. Step 1; Synthesis of amine bridges and step 2: immobilization of the synthesized amine bridges on silica surface. 


\section{List of Tables}

Table 1. Release kinetics of ibuprofen SBA-15 and SBA-15TPA in simulated gastric fluid (SGF), simulated body fluid (SBF) and simulated intestinal fluid (SIF), correlation coefficient $\left(\mathrm{R}^{2}\right)$, exponent $(n)$ and kinetic constant $(\mathrm{k})$ for $8.5 \mathrm{~h}$ at $310 \mathrm{~K} \pm 1$. 
List of Figures

Figure 1. IR spectra of (a) SBA-15 and modified silica (b) SBA-15TPA.

Figure 2. ${ }^{29} \mathrm{Si}$ NMR CP/MAS spectra of silicas (a) SBA-15 and SBA-15TPA and ${ }^{13} \mathrm{C}$ NMR CP/MAS spectrum of silica (b) SBA-15TPA.

Figure 3. Small angle X-ray diffractograms of mesoporous silicas (a) SBA-15, (b) SBA-15TPA, (c) SBA-15TPA loaded with ibuprofen.

Figure 4. Nitrogen sorption/desorption isotherms for silicas (a) SBA-15 and (b) SBA-15TPA.

Figure 5. SEM images of silica (A) SBA-15 (scale bars 1 $1 \mu \mathrm{m}$ ) and (B) SBA-15TPA (scale bars $1 \mu \mathrm{m})$ and (C) SBA-15/IBU (scale bars 5 $\mu \mathrm{m}$ ) magnifications x10000 and x5000 and TEM images of silicas (D) SBA-15 (scale bar $20 \mathrm{~nm}$ ) and (E) SBA-TPA (scale bars $50 \mathrm{~nm}$ ).

Figure 6. Thermogravimetric curves of silicas (a) SBA-15 and (b) SBA-15TPA.

Figure 7. In-vitro release profile of ibuprofen for first 8.5 hours (A) and complete release profile up to $75.5 \mathrm{~h}(\mathrm{~B})$ from SBA-15 (ש), SBA-15TPA (•) in SGF, SBA-15( $\triangle$ ) and SBA-15TPA $(\boldsymbol{\nabla})$ in SBF and from silicas SBA-15 ( $)$ and SBA-15TPA $(\triangleright)$ in SIF at $310 \mathrm{~K} \pm 1$. 


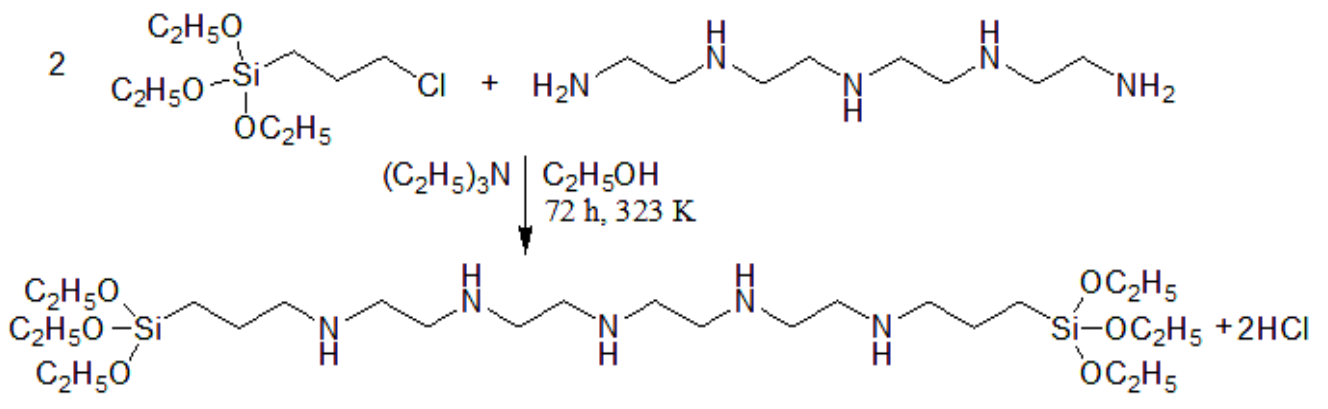

Step 1

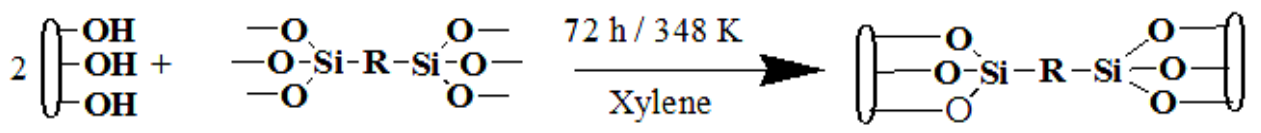

$$
\begin{aligned}
& \text { SBA-15 Bridged monomer (R) } \\
& \text { SBA-15TPA }
\end{aligned}
$$

Step 2

Scheme 1. 
Table 1.

\begin{tabular}{|c|c|c|c|c|c|c|c|c|c|}
\hline \multirow{3}{*}{ Silica } & \multirow{3}{*}{$\begin{array}{l}\text { Release } \\
\text { medium }\end{array}$} & \multicolumn{5}{|c|}{ Linear fit } & \multicolumn{3}{|c|}{ Non linear fit } \\
\hline & & $\begin{array}{l}\text { Zero } \\
\text { order }\end{array}$ & $\begin{array}{l}\text { First } \\
\text { order }\end{array}$ & $\begin{array}{l}\text { Higu } \\
\text {-chi }\end{array}$ & $\begin{array}{l}\text { Hixson- } \\
\text { Crowel }\end{array}$ & Peppas & \multicolumn{3}{|c|}{ Korsmeyer Peppas } \\
\hline & & $\mathrm{R}^{2}$ & $\mathrm{R}^{2}$ & $\mathrm{R}^{2}$ & $\mathrm{R}^{2}$ & $\mathrm{R}^{2}$ & $\mathrm{R}^{2}$ & K & $\mathrm{n}$ \\
\hline SBA-15 & \multirow{2}{*}{ SGF } & 0.37 & 0.38 & 0.7 & 0.31 & 0.66 & 0.98 & $6.30 \pm 0.43$ & $0.11 \pm 0.04$ \\
\hline SBA-15TPA & & 0.02 & 0.16 & 0.50 & -0.47 & -49.0 & 0.99 & $4.90 \pm 0.13$ & $0.03 \pm 0.02$ \\
\hline SBA-15 & \multirow{2}{*}{ SBF } & 0.48 & 0.49 & 0.73 & 0.34 & 0.61 & 0.96 & $14.50 \pm 2.7$ & $0.05 \pm 0.01$ \\
\hline SBA-15TPA & & 0.80 & 0.82 & 0.95 & 0.82 & 0.82 & 0.95 & $8.34 \pm 1.11$ & $0.41 \pm 0.07$ \\
\hline SBA-15 & \multirow{2}{*}{ SIF } & 0.64 & 0.64 & 0.85 & 0.62 & 0.70 & 0.90 & $14.20 \pm 2.22$ & $0.33 \pm 0.09$ \\
\hline SBA-15TPA & & 0.77 & 0.80 & 0.93 & 0.80 & 0.82 & 0.95 & $9.02 \pm 1.23$ & $0.39 \pm 0.07$ \\
\hline
\end{tabular}




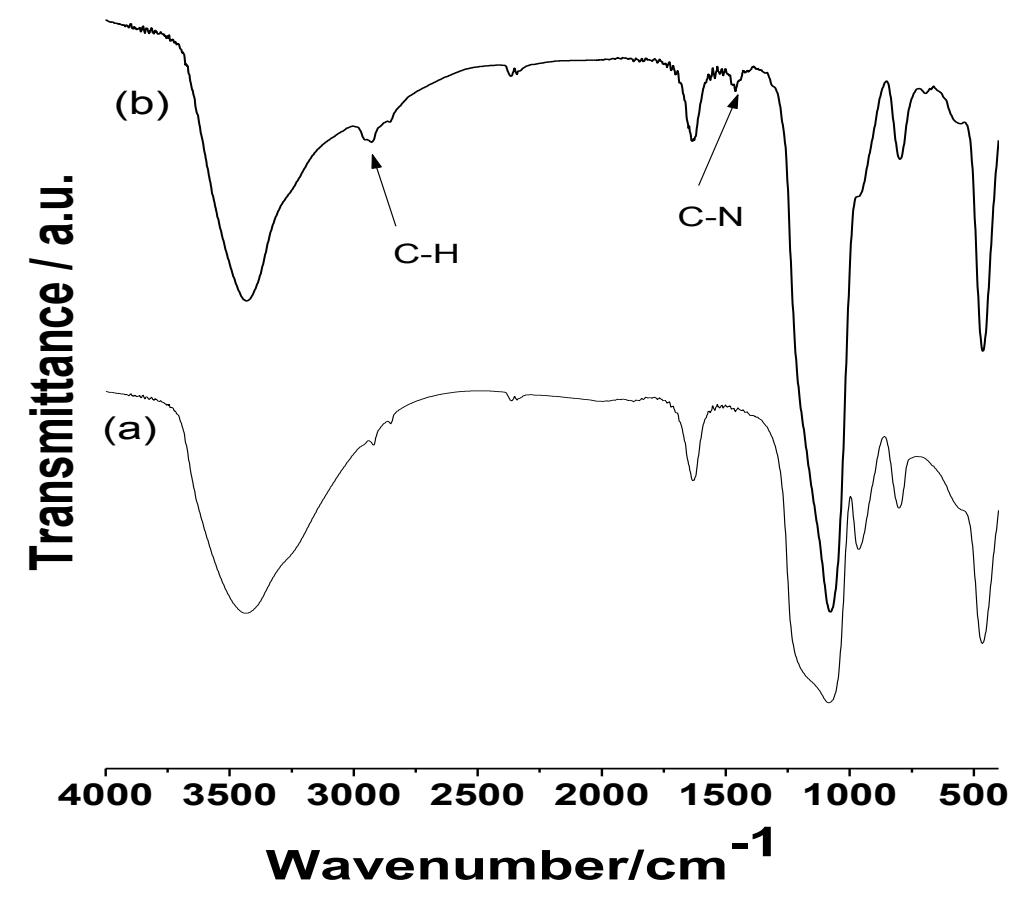

Figure 1 

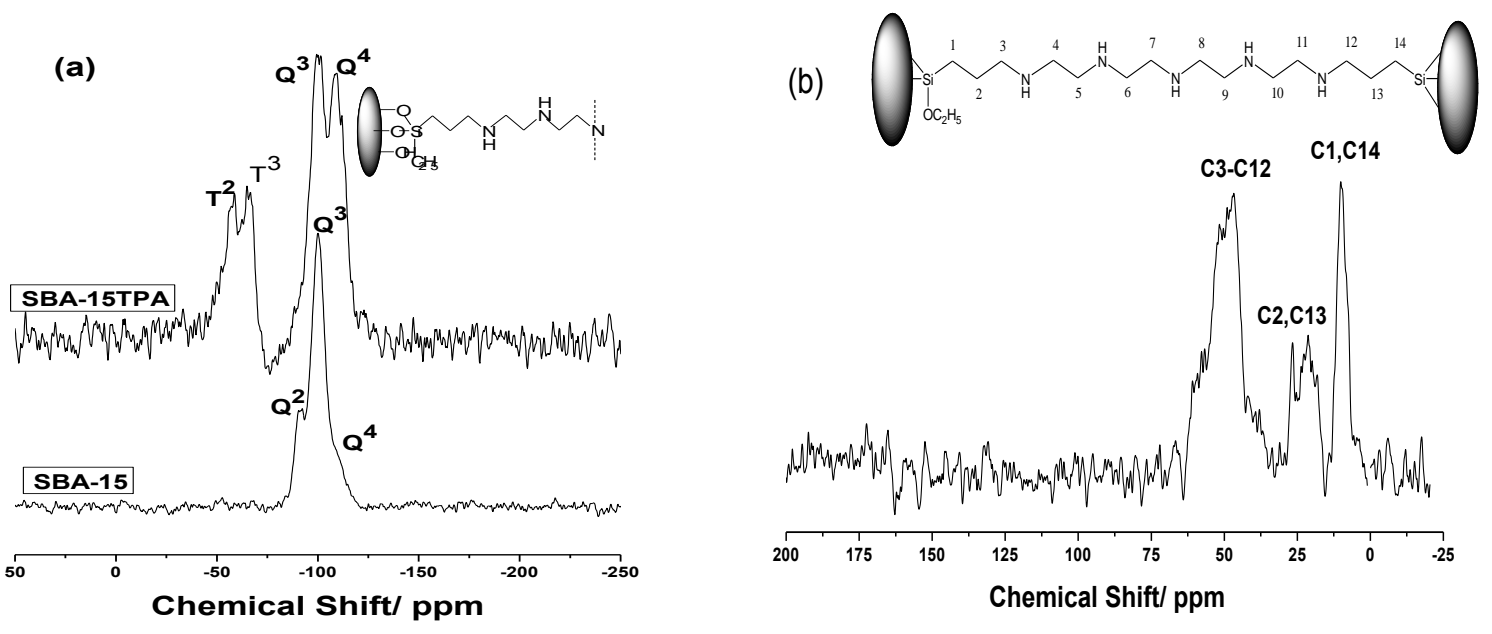

Figure 2. 


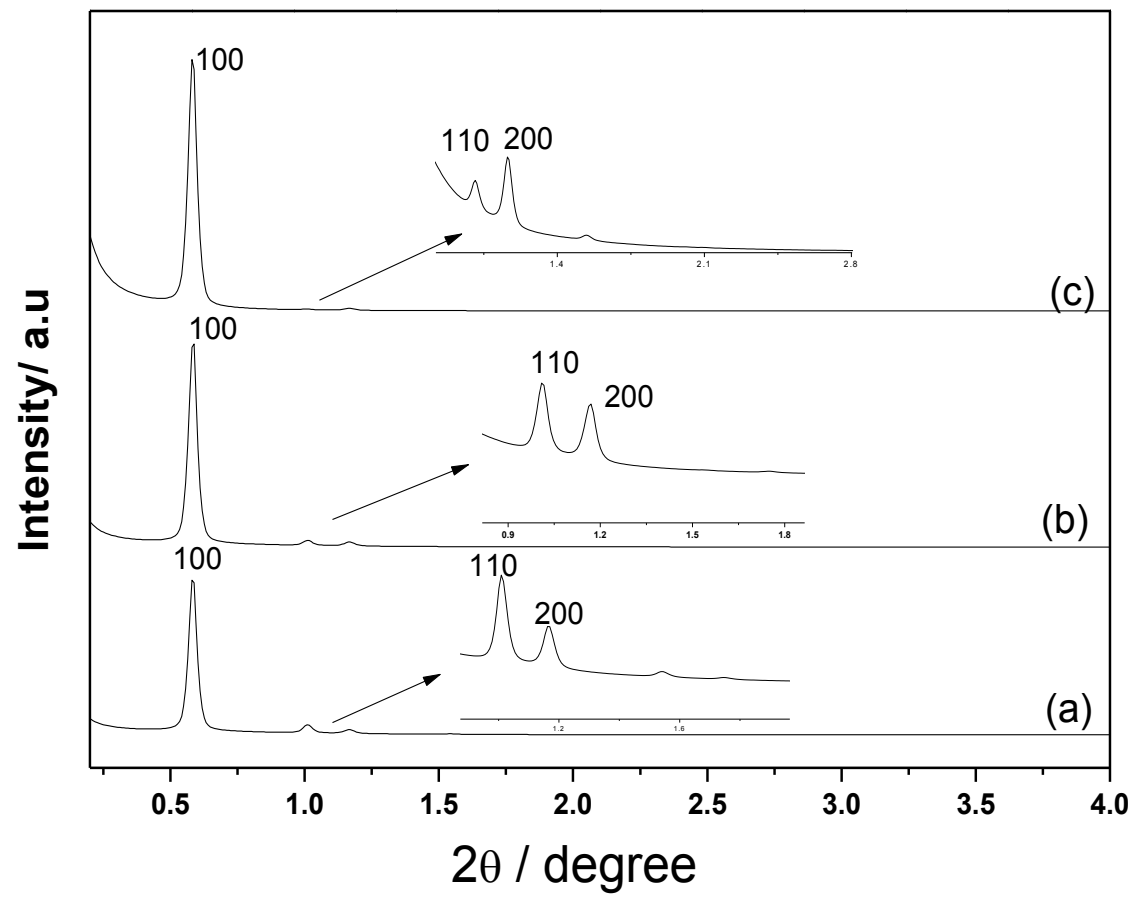

Figure 3. 


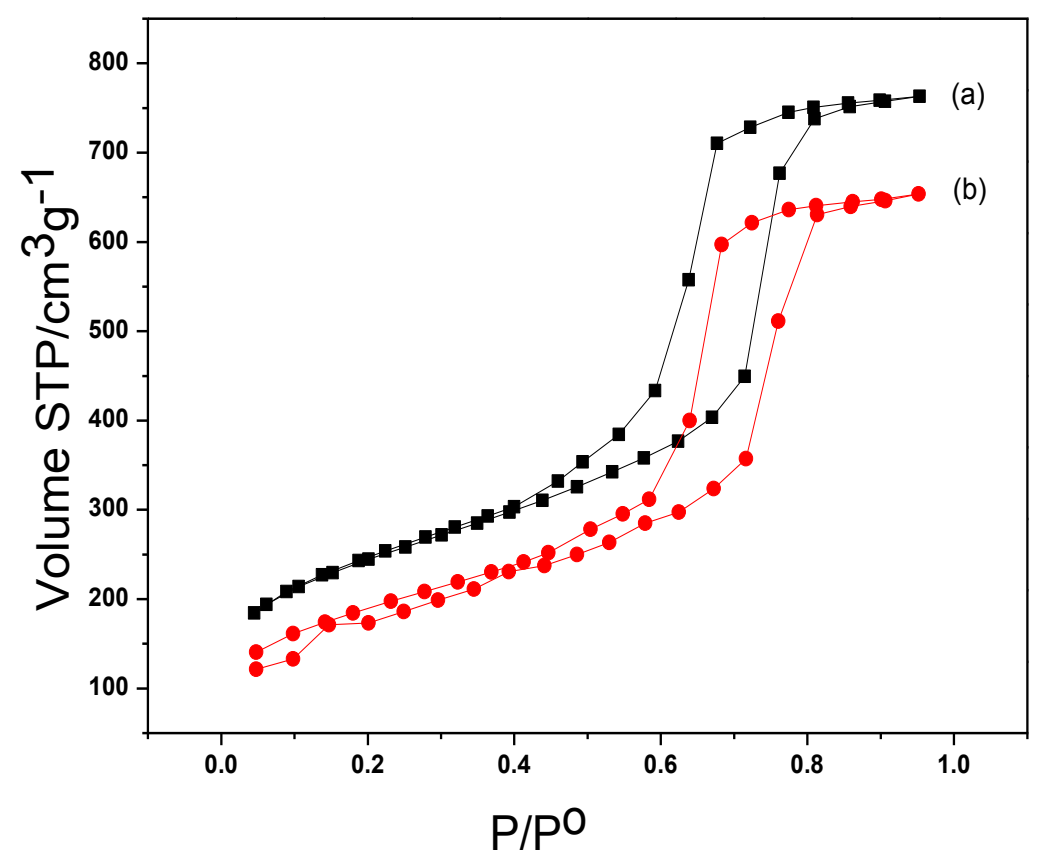

Figure 4. 

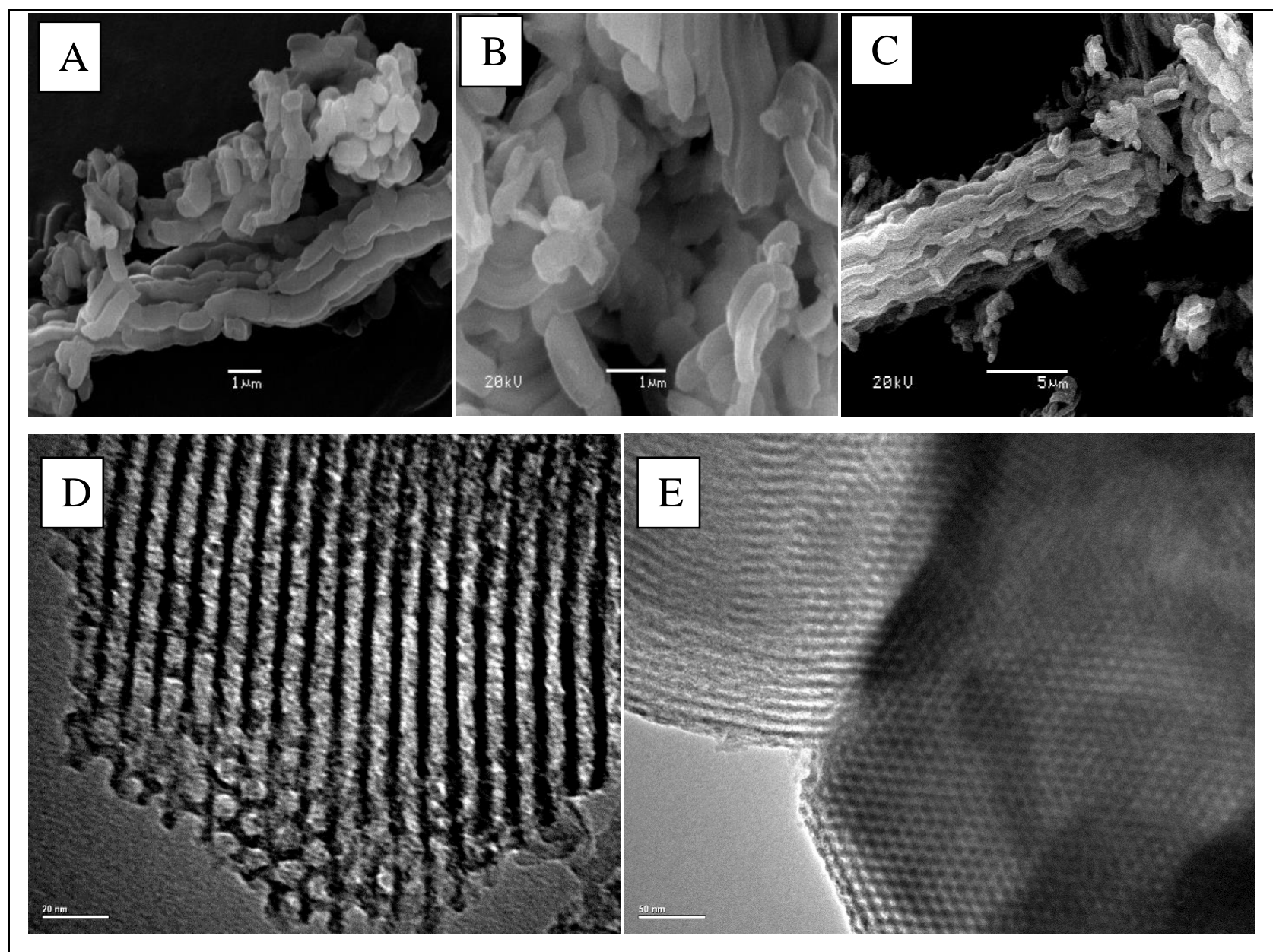

Figure 5. 


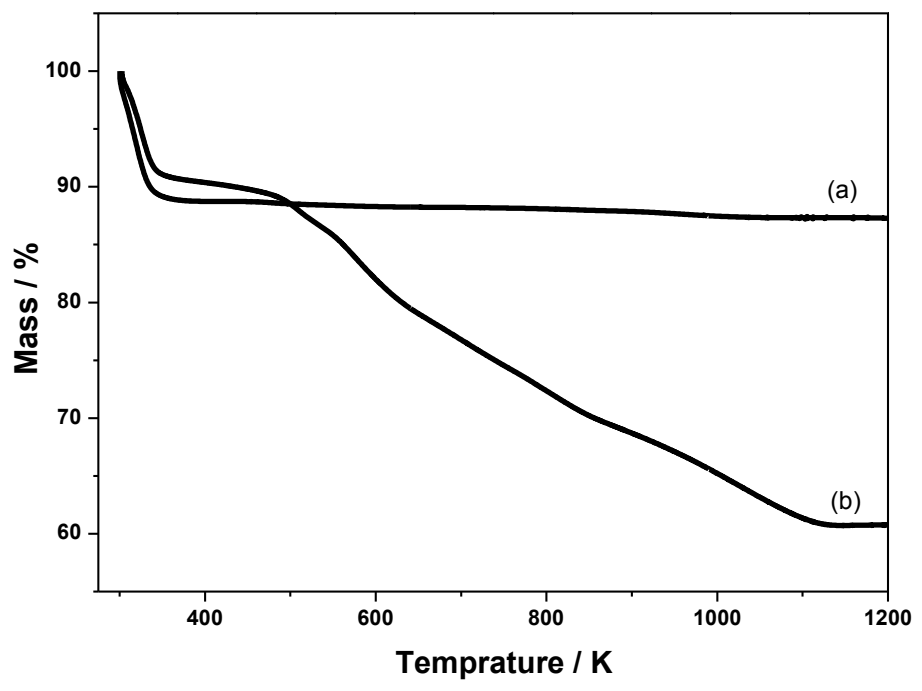

Figure 6. 

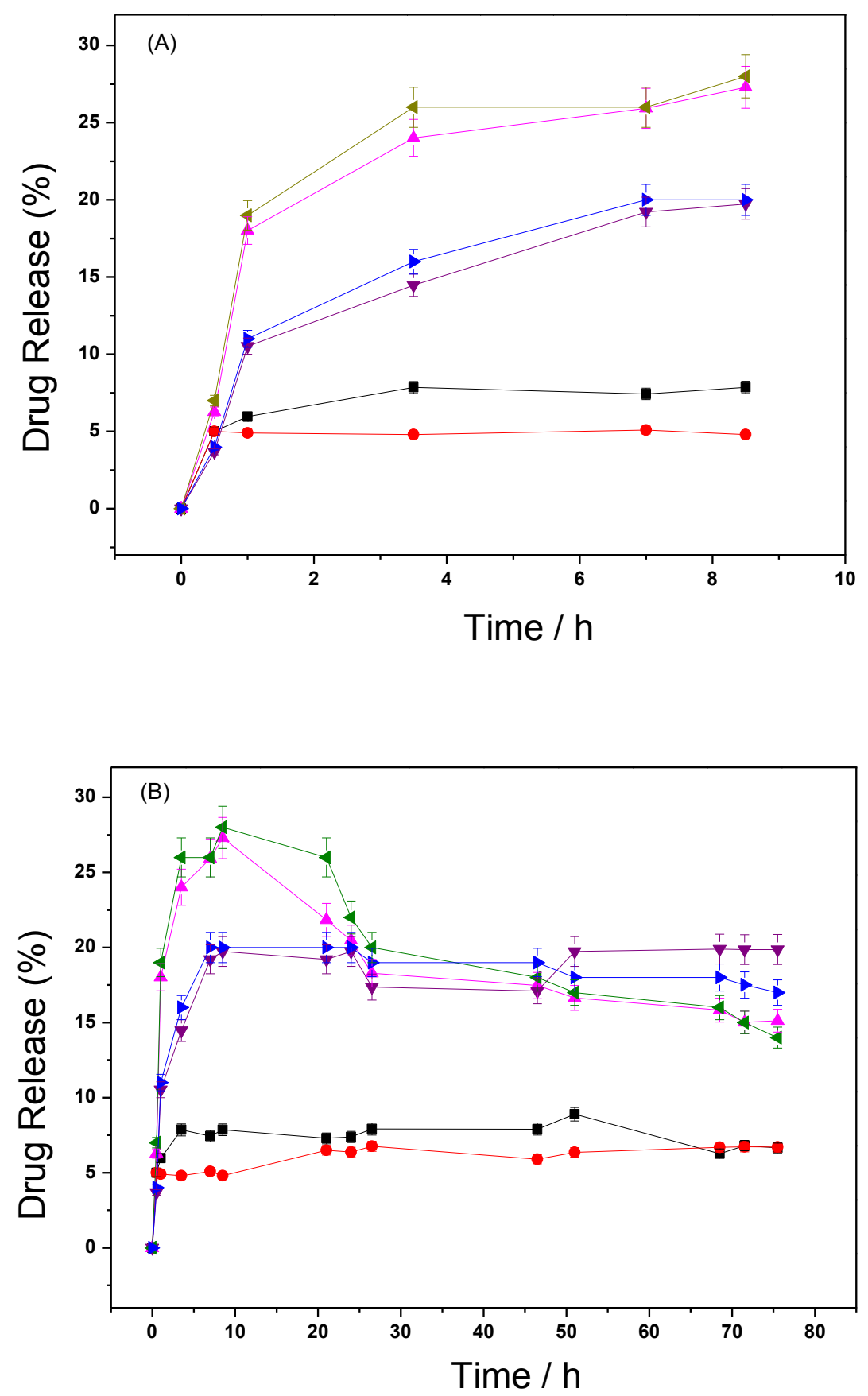

Figure 7. 